\title{
Глушкова Р.В.
}

\section{Информационная система дистанционного обучения «1С: Электронное обучение»}

Санкт-Петербургский государственный экономический университет (Россия, Санкт-Петербург)

doi:10.18411/sciencepublic-08-05-2020-08

idsp: sciencepublic-08-05-2020-08

Особенности современного мира, эпидемии, экономические кризисы вновь поставили вопрос о современных формах и методах обучения. Карантин, связанный с эпидемией коронавируса COVID-19 актуализировал тему дистанционного обучения и информационных систем дистанционного обучения.

Дистанционное обучение развивается не только в рамках национальных систем образования, но и отдельными коммерческими компаниями с преимущественной ориентацией на подготовку в области бизнеса.

Дистанционное обучение обладает уникальными потенциальными возможностями:

- предоставляет возможность проходить обучение, не покидая места жительства без отрыва от профессиональной деятельности;

- обеспечивает широкий доступ к образовательным отечественным и мировым ресурсам;

- предоставляет возможность организации процесса самообучения наиболее эффективным для себя образом и получения всех необходимых средств для самообучения;

- снижает стоимость обучения за счет доступности образовательных ресурсов;

- предоставляет возможность прерывания и продолжения образования в зависимости от индивидуальных возможностей и потребностей;

- значительно расширяется аудиторию обучаемых, которым доступны все виды образовательных ресурсов без возрастных ограничений;

- позволяет формировать уникальные образовательные программы за счет комбинирования курсов, предоставляемых образовательными учреждениями;

- позволяет повысить уровень образовательного потенциала общества и качества образования;

- удовлетворяет потребности страны в качественно подготовленных специалистах;

- повышает социальную и профессиональную мобильность населения, его предпринимательскую и социальную активности, расширяет кругозор и уровень самосознания;

- способствует сохранению и приумножению знаний, накопленных отечественной образовательной системой;

- способствует развитию единого образовательного пространства на территории РФ и зарубежных стран.

Преимущества дистанционного обучения особенно важны в период эпидемий, кризисов.

В настоящее время в мире накоплен значительный опыт реализации систем дистанционного обучения. Основные задачи и процессы, требующие автоматизации в системах дистанционного обучения следующие:

- Управление учебным процессом: формирование учебных групп, назначение преподавателей, составление плана обучения;

- Разработка электронных учебных курсов и тестов; 
- Создание глоссария терминов и определений;

- Учет и анализ результатов обучения и тестирования;

- Единая информационная среда: рассылки, учебные форумы и личные сообщения;

- Возможность использования в различных образовательных технологиях: электронное, аудиторное, смешанное обучение;

- Возможность импортаЭэспорта учебных курсов, результатов обучения и тестирования;

- Интеграция с основной, базовой информационной системой предприятия.

- Многоплатформенность, возможность работы в различных операционных системах.

Фирма «1C» разработала и успешно внедряет конфигурацию «1C: Электронное обучение» единственную систему дистанционного обучения, реализованную на платформе «1C: Предприятие 8». Данное решение фирмы «1C» создавалось на основании 10-летнего опыта реализации масштабных образовательных проектов.

«1С: Электронное обучение» автоматизирует бизнес процессы очного или дистанционного обучения.

Функционал конфигурации «1C: Электронное обучение» включает в себя:

- Наличие средств разработки электронных учебных материалов, с возможность импорта и экспорта данных в различные форматы;

- Возможности настройки различных видов учебных занятий и их характеристик

- Возможность проведения обучения в локальной сети и через Интернет;

- Возможность интеграции с другими конфигурациями системы $1 \mathrm{C}$, что позволяет организовать единое информационное пространство;

- Наличие встроенной системы личных сообщений, автоматических рассылок;

- Ведение учета и накопление статистики по каждому проведенному курсу: количество обучаемых, продолжительность обучения, оценки и другие показатели.

Конфигурация «1С: Электронное обучение» обеспечивает высокий уровень безопасности за счет применения специальных мер защиты персональных данных и учетной информации.

Bce решения (конфигурации), построенные на платформе «1C: Предприятие» поддерживают самые популярные операционные системы и СУБД: Linux, Windows, Mac OS, MS SQL Server, IBM DB2, Oracle Database, а так же отечественные операционные системы Astra Linux Special Editor, Альт 8 СП. обучение»:

Фирма 1C разработала несколько версий программ «1С: Электронное

«1C: Электронное обучение. Корпоративный университет» полнофункциональная система дистанционного обучения с максимальным функционалом. Данное решение универсально, можно настраивать для внутреннего обучения (аттестации) персонала производственного предприятия, можно в образовательной организации.

«1С: Электронное обучение. Веб-кабинет преподавателя и студента» позволяет организовать доступ к электронным курсам и их настройкам, интегрироваться при необходимости с версией «1C: Электронное обучение. Корпоративный университет».

«1С: Электронное обучение. Экзаменатор» упрощенная версия системы дистанционного обучения, с авторизацией по одному курсу или тесту. Данная версия 
позволяет разрабатывать электронные курсы и тесты, загружать или импортировать их по стандарту SCORM-2004 и в формате HTML. Поддерживается встроенная интеграция с программами кадрового учета - 1C:ERP, 1C:3УП, 1C:3ГУ

«1С: Электронное обучение. Конструктор курсов» однопользовательская программа для разработки электронных мультимедийных учебных курсов и тестов. Курсы и тесты, разработанные в Конструкторе курсов, используются следующим образом:

- переносятся в Корпоративный университет или Экзаменатор во внутреннем xml формате;

- публикуются в HTML формат в качестве самоучителя для автономного просмотра браузером;

- публикуются по стандарту SCORM-2004 для установки в стороннюю систему дистанционного обучения.

Стоимость программы «1C: Электронное обучение» составляет в зависимости от выбранной функциональности от 2900 руб. до 400 тыс. руб.

Удобный интерфейс, средства и механизмы программы обеспечивают быстрое освоение и использование программы. В программе реализовано всё самое необходимое для ведения электронного обучения сотрудников или студентов.

Таким образов, система «1C: Электронное обучение», полнофункциональная российская система дистанционного обучения, предназначенная для корпоративных учебных центров и образовательных, организаций полностью соответствует требованиям к данному классу программ

1. 1C: Предприятие 8 [Электронный ресурс] // 1C [Сайт]. [2012]. URL: https:// v8.1c.ru/elo// (дата обращения: 09.02.2020).

2. Барабанова М. И., Кияев В. И., Саитов А.В. Открытые системы и сети. Комплексная безопасность в системах и сетях современного предприятия; Учебник, под ред. проф. В. И. Кияева. - СПБ.: Изд-во СПбГЭУ, 2019. - 496 с.

3. Газуль С.М., Ананченко И.В., Кияев В.И. Проектирование прототипа клиентского устройства для гибридной информационной системы поддержки образовательного процесса в вузе // Современные проблемы науки и образования. — 2015, № 1; URL: www.science-education.ru/125-

\section{Котенко А.Л. \\ Влияние регулирования полной стоимости кредита на ломбардное предпринимательство}

МФПУ «Синергия»

(Россия, Москва)

doi:10.18411/sciencepublic-08-05-2020-09

idsp: sciencepublic-08-05-2020-09

\section{Аннотация}

В статье рассмотрено влияние ломбардов на долговую нагрузку россиян, а также последствия государственного регулирования полной стоимости кредита на ломбардное предпринимательство.

Ключевые слова: ломбард, полная стоимость кредита, микрофинансы.

Закредитованность россиян вызывает опасения у руководства страны и Центрального Банка, в последние годы принят ряд мер, направленных на снижение долговой нагрузки граждан, также включающие меры, ведущие к уменьшению доступности заемных средств для граждан. Регулирование имеет и оборотную сторону - влияние на бизнес, а именно снижение доходов занятых в нем людей. Инфраструктура современного финансового рынка достаточно широка, расходы на нее 